\title{
Frontières
}

\section{PEUR et peurs}

\section{Phrases}

\section{Réjane Charpentier}

Volume 12, numéro 2, printemps 2000

Peur bleue...

URI : https://id.erudit.org/iderudit/1074407ar

DOI : https://doi.org/10.7202/1074407ar

Aller au sommaire du numéro

Éditeur(s)

Université du Québec à Montréal

ISSN

1180-3479 (imprimé)

1916-0976 (numérique)

Découvrir la revue

Citer ce document

Charpentier, R. (2000). PEUR et peurs : phrases. Frontières, 12(2), 79-79.

https://doi.org/10.7202/1074407ar

Ce document est protégé par la loi sur le droit d'auteur. L'utilisation des services d'Érudit (y compris la reproduction) est assujettie à sa politique d'utilisation que vous pouvez consulter en ligne.

https://apropos.erudit.org/fr/usagers/politique-dutilisation/
Cet article est diffusé et préservé par Érudit.

Érudit est un consortium interuniversitaire sans but lucratif composé de l’Université de Montréal, l'Université Laval et l'Université du Québec à Montréal. Il a pour mission la promotion et la valorisation de la recherche. https://www.erudit.org/fr/ 


\section{PEUR et peurs Phrases}

Il y a une PEUR nécessaire. Quand elle nous atteint, elle prend la situation en main, nous fait fuir ou combattre sans notre consentement et, si nous refusons d'agir efficacement, nous laisse mourir sans pitié. Il y a d'autres peurs: celles que notre instinct juge indignes de sa puissante intervention et qu'il abandonne à notre raison.

Pour qui n'a pas accès aux jouissances du sentiment et de l'esprit, il n'existe que des besoins inassouvissables et des peurs jalousement entretenues.

On ne peut perdre ce qu'on ne possède pas. Étant donné le monde dans lequel nous vivons ceux qui n'ont pas peur feraient bien de se demander s'il ont encore toute leur tête.

La peur est ce feu de circulation qui tourne au rouge quand ça va mal. Son signal est clair: ARRÊT. L'arrêt repose le cœur et donne le temps de réfléchir.

Le mot peur est un nom. C'est indigne de lui. Il mériterait d'être un verbe - «mot variable qui exprime une action, un état, un devenir».

Le verbe peurer se conjuguerait comme le verbe pleurer à tous les temps, à toutes les formes et à toutes les sauces.

Pourquoi ne pas l'admettre: nous peurons tous. Je suis venue peurer avec vous.
D'abord - d'abordage! - il est nécessaire de le savoir quand on a peur. Alors on est capable de se le faire savoir! C'està-dire de s'assurer que les vingt cohortes d'anges et les cent légions de diables qui habitent nos psychés sont au courant de la situation.

Étant donné la peur, s'en parler, s'en parler, s'en parler. Ou mieux encore, se l'écrire. S'en parler ou se l'écrire aussi longtemps qu'il le faut pour réaliser que la parole ou l'écriture a remplacé la peur.

Avoir peur d'avoir honte d'avoir peur c'est le comble de la servitude.

La peur et l'espérance sont deux sœurs jumelles mises au monde par des êtres de pouvoir: prêtres, ministres, professionnels, parents...

Pourquoi choisir entre la peur et la tranquillité lorsqu'il est possible de les conjuguer?

La plus idiote des peurs, la plus frivole, si elle est considérée avec une profonde attention, peut être une source de plaisir pour l'esprit.

Quoi! Vous voulez me faire peur? Je me déchargerais de mes responsabilités sur les professionnels de la santé lorsque viendrait le temps de mourir? À quoi m'aurait servi d'enlever aux prêtres la responsabilité de mon «âme» si c'était pour laisser celle de mon corps aux médecins! Je demande la prescription d'un cocktail létal au nom de ma dignité et de ma liberté de choix.

C'est ca, me dit la peur: distrais-toi! Regarde ailleurs pour ne pas me voir. Je grandis plus à l'aise quand je ne suis ni vue ni connue.

On ne peut pas devenir conscient inconsciemment et sans conscience, la vie n'est que peurs, vaciliements et distractions.

La peur est notre ange de Jacob. Ou bien nous accepterons de combattre avec jusqu'à ce qu'elle dévoile son nom ou bien elle nous rongera la peau jusqu'à l'os.

Mais qui nous racontera les charmes de la peur?

Réjane Charpentier, phraseuse 